\title{
Perception of Decent Work and the Future Among Low Educated Youths in Brazil and Portugal
}

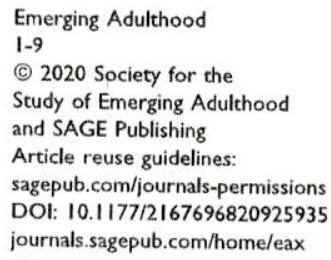

journals.sagepub.com/home/eax

(9) SAGE

\author{
Marcelo Afonso Ribeiro' ${ }^{\oplus}$, Paulo Miguel Cardoso ${ }^{2}$, \\ Maria Eduarda Duarte ${ }^{3}$, Beatriz Machado ${ }^{4}$, \\ Paula Morais Figueiredo ${ }^{5}$, \\ and Guilherme de Oliveira Silva Fonçatti ${ }^{5}$
}

\begin{abstract}
Brazil and Portugal have different working contexts. In Brazil, mixed formal and informal ways dominate, while in Portugal, formal working contexts prevail. By means of in-depth interviews, this study sought to understand and compare the perception of decent work and future among 32 low-qualified emerging adults in Brazil and Portugal. The data from participants' interviews were analyzed using Consensual Qualitative Research. Findings showed that Portuguese participants sought the International Labour Organization's features for a decent work associated with fair income, social integration, self-realization at work, and family support, while the Brazilian sample had searched for better living conditions, respect, social recognition, and social protection. Thus, in contexts of greater vulnerability, the participants do not perceive their work as a source for self-determination and social recognition. This is a key point for understanding identity construction and life narratives of emerging adults in vulnerable working situations.
\end{abstract}

\section{Keywords}

decent work, identity, young adults, career counseling, life design.

Nowadays, the world of work is characterized by complexity, heterogeneity, flexibilization, reduction of workers' rights, and inequality of work opportunities, which has generated informal and precarious work, as well as unemployment (Antunes, 2015; Castel, 2000). In this context, the International Labour Organization (ILO, 1999) has proposed an agenda to foster decent work, which

\footnotetext{
involves opportunities for work that is productive and delivers a fair income, security in the workplace and social protection for families, better prospects for personal development and social integration, freedom for people to express their concerns, organize, and participate in the decisions that affect their lives, and equality of opportunity and treatment for all women and men.
}

Since the ILO has presented a proposal for increasing decent work, the subject has been widely debated. In this process, three topics deserve to be highlighted: (1) the use of formal employment as a model for decent work (Hauf, 2015), (2) the need to eliminate informality in work (Spink, 2007), and (3) the concept of scope and universality in decent work (Di Ruggiero et al., 2015; Hauf, 2015). The last topic raises the question of whether there is a decent work model or different versions of decent work, which vary according to the national and cultural contexts where they occur.

Research developed by the ILO and the Organization for Economic Co-operation and Development (OECD) shows that, for youngsters, it is hard to access decent work in developed countries, as well as in both developing and underdeveloped

\footnotetext{
'Instituto de Psicologia da Universidade de São Paulo, University of São Paulo, Brasil

${ }^{2}$ Center for Advanced Studies in Management and Economics, University of Évora, Portugal

${ }^{3} \mathrm{CICPSI}$, Faculty of Psychology, University of Lisbon, Portugal

${ }^{4}$ University of Lisbon, Portugal

${ }^{5}$ University of São Paulo, Brazil
}

\section{Corresponding Author:}

Marcelo Afonso Ribeiro, PhD, Social Psychology, Instituto de Psicologia da Universidade de São Paulo, University of São Paulo, Av. Prof. Mello Moraes, 1721. CEP 05508-030, São Paulo, Brasil.

Email: marcelopsi@usp.br 